\title{
LOS LÍMITES DE LA ECONOMÍA ECOLÓGICA EN LA ERA DEL CAPITALOCENO
}

\section{THE LIMITS OF THE ECOLOGICAL ECONOMICS IN THE ERA OF CAPITALOCENE}

\author{
Alejandro Escalera Briceño* \\ Manuel Ángeles Villa** \\ Alejandro Palafox Muñoz ${ }^{* * *}$
}

\section{RESUMEN}

En este documento se ofrece una reflexión sobre las formas en que la economía ecológica, en sus diversas manifestaciones, ha abordado la crisis socioambiental en curso, $y$ a la vez plantea los límites de esa heterogénea disciplina a través de un análisis fundamentado en el concepto del metabolismo social, apoyado por un acercamiento de los "Cuatro Baratos" que recientemente trajera Jason Moore a la discusión de los efectos del capitalismo para el entorno natural.

PALABRAS CLAVE: CRISIS SOCIOAMBIENTAL * ECONOMÍA VERDE * MARXISMO * CAPITALISMO * RECURSOS NATURALES

\section{ABSTRACT}

This paper offers some reflections on the ways in which ecological economics, in its various manifestations, approaches the ongoing ecological crisis. At the same time, it discusses the limits of that heterogeneous discipline by means of an analysis based on the concept of social metabolism that makes use of Jason Moore's recent theorizations on the effects of capitalism on the environment.

KEYWORDS: ENVIRONMENTAL CRISIS * GREEN ECONOMY * MARXISM * CAPITALISM * NATURAL RESOURCES

* Departamento de Estudios Sociales y Empresariales de la Universidad de Quintana Roo, Unidad Académica Cozumel, México.

escalera2482@gmail.com

** Departamento de Economía de la Universidad Autónoma de Baja California Sur, México. manan@uabcs.mx.

*** Departamento de Estudios Sociales y Empresariales de la Universidad de Quintana Roo, Unidad Académica Cozumel, México. palafox@uqroo.edu.mx. 


\section{INTRODUCCIÓN}

La inspiración de este texto surge de una presentación de los autores en el seno del III Congreso de la Sociedad Mesoamericana de Economía Ecológica (cosmeE), celebrado a finales de 2016 en el Recinto de Mayagüez de la Universidad de Puerto Rico, con el objetivo de reflexionar sobre las formas de lograr un pluralismo metodológico en el estudio de las relaciones ser humano-naturaleza, enfatizando la multidisciplinariedad. Significativamente, buena parte de las ponencias que allí se presentaron se vinculaban con la valoración de la naturaleza a través de diversos métodos, sobresaliendo entre ellos el de costo-beneficio, que caracteriza a la Economía Ambiental (EA) que, fundamentada en la teoría económica neoclásica, constituye el principal rival disciplinario de ciertas vertientes de la Economía Ecológica (EE) ${ }^{1}$.

La evidente similitud metodológica hizo procedente la crítica a la EE que se engloba en el presente trabajo, que a la vez lleva a la profundización de la reflexión sobre los procesos metabólicos con base en el estado del arte de la disertación doctoral (aún en curso) de Alejandro Escalera, El turismo como catalizador de la brecha metabólica en el marco del imperialismo ecológico. Así pues, en la primera sección del documento se hace una breve semblanza del desarrollo evolutivo de la EE con énfasis en consideraciones metodológicas, en particular al nivel macro, que subrayan los límites del crecimiento económico.

A la vez, con fundamento en la caracterización de Barkin, Fuente y Tagle (2012), se reconoce dentro de la eE la coexistencia de tres versiones: a) la conservadora, b) la crítica y c) la radical. La diferencia principal estriba en que las corrientes conservadora y crítica buscan la "sustentabilidad" (en variadas definiciones y a diversas escalas) en el marco del actual sistema socioeconómico (el capitalismo), mientras que

$1 \quad$ En contraste, nuestra participación tomó la forma de una ponencia crítica hacia la EE con respecto a los modelos metabólicos. Otra línea de investigación presentada en el evento, con un enfoque decididamente opuesto a la ortodoxia, fue el de la Ecología Política. la versión radical plantea la necesidad de una ruptura con la racionalidad económica de ese proyecto civilizatorio. Asimismo, se identifican algunas de las limitaciones de la EE en las primeras dos versiones mediante el empleo del concepto de la brecha metabólica, cuya génesis radica en las transferencias de insumos biológicos promovidas por la monopolización de los recursos naturales, el imperialismo ecológico y en general, la intensificación de las relaciones de producción y sociales capitalistas. En esta sección, el marxismo ecológico destaca como el ala crítica de un proyecto modernizador que aún no concluye 2 . En el segundo apartado, sobre el metabolismo social, se busca mirar de nuevo la interpretación de Marx con el propósito de cuestionar los circuitos metabólicos que se construyen con la finalidad de imponer cambios de estilo de vida. Por último, en el apartado sobre la brecha metabólica se destacan las dinámicas de la acumulación de capital en la era del capitaloceno (Moore, 2015), con énfasis en el pensamiento dialéctico, que difiere sustancialmente de los enfoques posmodernos que, cada vez más, parecen alimentar ciertas vertientes de la EE.

\section{LA ECONOMÍA ECOLÓGICA COMO CAMPO EMERGENTE}

El capitalismo requiere el progreso constante y se caracteriza por alinear los avances tecnológicos a las fuerzas productivas para continuar impulsando la reproducción ampliada del capital. La intensificación del sistema capitalista trae consigo patrones de producción social y ambientalmente destructivos que amenazan rebasar las fronteras ecológicas planetarias cuyo proceso ocasionaría un efecto de no retorno atentando contra la vida entera de la biosfera.

Es a partir de mediados del siglo xx cuando empieza a darse una toma de consciencia sobre la degradación ambiental, asociada a los procesos de crecimiento económico al hacerse

\footnotetext{
$2 \quad$ Es esencial reconocer la diferencia entre modernismo, modernización y modernidad. En término general, esta última coincide con el capitalismo. Véase Anderson (1984).
} 
claro el deterioro en distintas escalas (Leff, 2011). Ante esta perspectiva se hace evidente que, más allá de la destrucción creativa relacionada con la industrialización en buena parte del globo, el acelerado repunte del intercambio planetario de mercancías, y los consuetudinarios sube y bajas del sistema, se asiste a una crisis multidimensional que abarca lo económico, lo financiero, lo energético, lo ecológico y lo político (Ángeles, Gámez e Ivanova, 2011; Guillen, 2015).

Sin duda, se trata de un modo de producción que ya rebasa los límites planetarios al amenazar la capacidad de regeneración del ambiente natural a la velocidad requerida por las altas tasas de acumulación. La pérdida de ecosistemas por el uso y abuso de los combustibles fósiles forman parte de las contradicciones del capitalismo avanzado (Malm, 2016), que se han agudizado en la era de la acumulación flexible (el modelo neoliberal), aún con el empleo de estrategias "sustentables" como las diseñadas en el seno de los modelos del llamado capitalismo verde (Smith, 2015).

Esta problemática ocasionó el surgimiento de diferentes corrientes para explicar el origen y las posibles soluciones a la crisis ambiental. Desde la óptica de la Economía Ambiental (EA) cobraron importancia metodologías para estimar el óptimo de contaminación con fundamento en el análisis costo-beneficio y la valoración de los bienes ambientales con base en estudios econométricos, que a su vez dependen de las expresiones de determinados grupos de su disponibilidad a pagar por el uso del recurso, o bien, que se les pague si otro lo usa.

Al mismo tiempo empezó a surgir otra alternativa cuya intención es evidenciar la racionalidad moderna con los límites biofísicos, el carácter entrópico de las actividades económicas del ser humano ( $y$ de la vida misma), y la búsqueda de una reducción significativa con los insumos naturales que intervienen en el proceso productivo, así como, el rechazo de estilos de vida fundamentados en el crecimiento del consumo de bienes materiales. De esta manera emerge la Economía Ecológica (EE), definida por uno de sus más notables expositores, Robert Costanza como "la ciencia y manejo de la sustentabilidad" (Martínez-Alier y Schlüpmann, 1991), pues a grandes trazos es una nueva disciplina híbrida de la economía que ofrece un "enfoque multidisciplinario, el pluralismo metodológico, y la apertura a consideraciones de tipo histórico-institucionales para entender los problemas ecológicos y sociales" (Burkett, 2008, p. 22) ${ }^{3}$.

El antecedente de la EE se encuentra en el trabajo de Podolinsky de 1880, El trabajo humano y su relación con la distribución de la energía, esta obra tuvo cinco versiones y ostentó títulos diferentes con el fin de ser revisada por diversos expertos, en aquel momento se fundamentó desde una perspectiva económica para abordarla como un sistema de conversión de energía, se apoyó en comparaciones con diversos ecosistemas rurales que abarcaban bosques y prados, a su vez incorporó los entornos producidos por los seres humanos, por mencionar, los prados artificiales y los campos agrícolas, también demostró que la producción de biomasa incrementaba cuando era mayor el trabajo humano y el animal (Podolinsky, 1995; Foster y Burkett, 2004).

A mediados del siglo xx, la eE comenzó a ser un campo alternativo para proponer límites al crecimiento económico, fundamentados sobre todo en las obras de Georgescu-Roegen quien indicó que el proceso económico estaba (aún lo está) sujeto a la gobernabilidad de las leyes de la entropía, además enfatizó que era irreversible por la constante transformación de materia y de energía en residuos no susceptibles de un uso ulterior por el ser humano (con una alta entropía), el carácter entrópico de los procesos económicos fue esencial para engarzarla con la segunda ley de la termodinámica, por consiguiente, le sirvió para fundamentar

$\overline{3} \quad$ De entrada se subraya que la EE se apoya de otros campos disciplinarios, como la ecología industrial, la agro-ecología, la historia ambiental, por tanto, han logrado construir un metabolismo social que se encuentra en los trabajos de Robert U. Ayres, Herman Daly, Joan Martínez-Alier, René Passet, Manfred Max-Neef, Víctor Toledo, José Manuel Naredo, Oscar Carpintero, Marina FischerKowalski, Mario Giampietro, John McNeill, Joshua Farley, Roldán Muradian, Walter Pengue y otros más (véase Martinez-Alier, 2008). 
un cuarto principio relacionado con la materia, por este motivo afirmó que durante el uso de materiales existe energía que se degrada sin poder recuperarla, en aquel momento quería explicar que el crecimiento económico reducía los recursos naturales de tal forma que generaba escasez (Georgescu-Roegen, 1996).

Kenneth Boulding, otro de los fundadores modernos de la EE, es especialmente recordado por un famoso ensayo en el que empleó la figura de "la nave espacial llamada Tierra", que le sirvió para exponer los límites planetarios por la finitud de los recursos (Boulding, 1996). Herman Daly, otrora funcionario del Banco Mundial y ex alumno de Georgescu-Roegen, argumenta que el crecimiento sostenido de la producción y el consumo de largo plazo podría ser válido únicamente si se cumpliera alguna de las siguientes tres condiciones: a) si la economía no fuera un subsistema, b) si la economía creciera en una dimensión que no involucrara al aspecto físico y c) si se derogaran las leyes de la termodinámica (Daly, 2009).

Más recientemente, Daly ha recordado que en sus tiempos en el Banco Mundial con frecuencia escuchó la afirmación sobre que "no existe conflicto entre la economía y la ecología: podemos $y$ debemos hacer crecer la economía $y$ proteger al medio ambiente al mismo tiempo" (Daly, 2015, p. 1). De esto último evoca los postulados de la economía verde en el sentido de que el cambio tecnológico y el mercado son mecanismos suficientes (óptimos) para cuidar al planeta. Para Daly (2015), esta es una verdad a medias, por una parte, su visión es que la microeconomía es el ámbito decisorio adecuado para la asignación de recursos entre lo más y lo menos deseado; por la otra, rechaza la macroeconomía por enfocarse sobre todo en el crecimiento económico medido por el Producto Interno Bruto (PIB).

Lo primero, el mercado como mecanismo de asignación de recursos, es deseable, mientras que el crecimiento de las dimensiones físicas de la economía es imposible en un planeta finito, frase recurrente en la Ee. Daly (2009) postula la alternativa de "estado estable", reminiscente de las teorizaciones clásicas de David Ricardo (1973) y de John Stuart Mill (2009), a saber, un capitalismo sin crecimiento, que con conocimiento de causa, Ricardo declaraba una imposibilidad. El "decrecimiento" de Serge Latouche (2010) y otros defensores europeos del medio ambiente, enarbolan una bandera similar (Cariño, Ángeles, Castorena y Amao, 2014).

La intención de Latouche en esta obra es revertir la espiral de las cada vez más insistentes presiones del crecimiento y el consumo, para propiciar una existencia más serena que descanse en la calidad de vida, la solidaridad $y$ el respeto al medio ambiente (Ibíd.). Los críticos del Estado estable y del decrecimiento insisten que estas son meramente posturas voluntaristas que minimizan importantes problemáticas, de suma relevancia sociológica, que tienen que ver con el trabajo, la población $y$ la sociedad, $y$ revelan fuertes afinidades con el concepto neoliberal de la "buena gobernanza" (Markantonatu, 2013).

\section{EL MARXISMO ECOLÓGICO COMO VERSIÓN RADICAL DENTRO DE LA ECONOMÍA ECOLÓGICA}

Conviene subrayar que en la actualidad coexisten la Ee conservadora, la eE crítica y la eE radical, cada una con sus propias metodologías (Barkin, Fuente y Tagle, 2012). La EE en su parte conservadora destaca su apego a la economía neoclásica por respaldar el crecimiento económico (Ibíd.), debido a lo cual con impuestos ecológicos o con permisos de contaminación transables se pueden arreglar los fallos del mercado (Martínez-Alier, 2008). Esta vertiente enseña una segunda careta que propone un decrecimiento económico con el indigenismo latinoamericano, estas dos mascaras a pesar de presentar una rivalidad comparten una perspectiva ética ambiental (Barkin, Fuente y Tagle, 2012). Si bien, Daly es enérgico al criticar este crecimiento por la falsa promesa que algún día beneficiará a todos, por eso pone en duda que la economía sea medida con el pIB real o el rendimiento de los recursos (Daly, 2012). Por su parte, la EE crítica a las externalidades, las cuales atribuye como fallos del gobierno por imponer una estructura de derechos de propiedad sobre el ambiente o el subsidio a las actividades nocivas, desde esta postura se reconocen los 
conflictos ecológicos distributivos y el de justicia ambiental (Martínez-Alier, 2011 y 2008). Esta EE tiene la particularidad que se conecta con la Ecología Política (ЕР), ambas pretenden analizar los procesos complejos globalizados de los conflictos entre la naturaleza y los seres humanos. Consecuentemente dejan fuera al marxismo por su pensamiento dialéctico, principalmente por su falta de aportación de Marx por concederle poca importancia a la segunda ley de la termodinámica cuando Thompson la explicó a mediados del siglo xix (Martínez-Alier, 2003). También reclaman la ausencia de una historiografía marxista sobre los presupuestos cuantitativos y cualitativos del metabolismo social en la cual no representó apropiadamente los materiales de la naturaleza y energéticos de la sociedad humana (Sevilla, 2011).

En el siglo xix era inimaginable una catástrofe ecológica planetaria, sin embargo, Marx con su materialismo práctico podía entender el funcionamiento del modo de producción capitalista y acercarse a la crisis ecológica (sin desarrollarla por completo). Por su parte, Foster ha demostrado que el teórico alemán tuvo interés sobre los experimentos que señalaban las emisiones de dióxido de carbono que contribuían al efecto invernadero, así como, las notas que tomaba acerca de la forma en que el movimiento de las isotermas sobre la superficie terrestre (debido al cambio climático), llevaba a la extinción de especies a lo largo del curso de la historia de la Tierra (Foster, 2000 y 2015).

Ahora, la eE radical busca una ruptura con la postura de la racionalidad económica (Barkin, Fuente y Tagle, 2012), los marxistas ecológicos reclaman los cambios de estilo de vida al incorporar las leyes de la entropía, así que enfatizan la existencia de un proletariado ecológico subsistiendo bajo un esquema de conteo de transferencias de materia-ecológica para continuar sosteniendo el costo de vida de unos pocos (Foster, 2015). Esta versión de la eE apuesta en cambio por un materialismo ecológico en el que se exponga la incesante mercantilización de la naturaleza y la acumulación de capital (Schmidt, 2013).

Una de las primeras aportaciones fueron las de Schmidt con su trabajo El concepto de naturaleza en Marx, en la cual rescató un pensamiento filosófico de la naturaleza que se hallaba en las concepciones como: materia, sustancia natural, cosa natural, tierra, momentos existenciales, objetivos de trabajo, condiciones objetivas y fácticas del trabajo (Schmidt, 2011). La obra antes mencionada fue terminada de redactar en 1962 sin que se conocieran las nociones de: a) la conciencia ecológica, b) los límites del crecimiento, c) civilización alternativa y d) la crisis ecológica (Schmidt, 2013).

Desde los 90, el marxismo ecológico se coloca como una perspectiva importante, la contribución de Foster pone en el centro de la atención la cuestión del trabajo y la naturaleza a un público más amplio (los investigadores de las ciencias naturales) (Foster, 2000). Los marxistas ecológicos adoptaron el reto de renovar las categorías del materialismo histórico $y$ dialéctico creadas por el teórico alemán, el propósito es aplicar una indagatoria al capitalismo avanzado con la intención de exponer que la acumulación de capital desde su origen ha organizado a la naturaleza de forma eficiente. La postura radical de la eE no trata de pintar de verde al marxismo, pero sí, de explorar el desarrollo económico y tecnológico del capitalismo para evidenciar que sus efectos conducen a algo desconocido para todos los seres vivos del planeta, en el que las condiciones de vida están cambiando vertiginosamente.

Por otra parte, los ecosocialistas abrazan el pensamiento marxista para insertar una visión renovada de la economía política al colocar la consigna de "cambio sistémico, no cambio climático" (Foster, 2015). De esto se dibuja una reflexión y reelaboración del pensamiento dialéctico desde la perspectiva ambiental (Leff, 2003). El ecosocialista James O'Connor es un referente de esta corriente con su segunda contradicción en la cual hace referencia a las condiciones de producción (el capital no produce la fuerza de trabajo, la naturaleza externa $y$ la infraestructura urbana), más bien, resalta todos los factores externos que no contempla el capital, de tal suerte los movimientos sociales sin ser exclusivamente obreros sino plurales $y$ diversos (múltiples movimientos sociales como los ambientalistas, los feministas, etc.) impulsarían 
a relaciones sociales ecológicamente sostenibles (O’Connor, 2001).

El químico Paul Crutzen (2002) acuñó el término "antropoceno" para hacer referencia a una era geológica encaminada a la industrialización a partir de la revolución industrial. Esta etapa histórica se apega al uso desmedido de la energía fósil, que induce a una conjunción de distintas áreas científicas (la climatología, la economía, la política, etc.) de tal forma que logran resaltar una narrativa catastrófica de la humanidad alrededor del cambio climático y otros procesos que pueden llevar a la extinción de la especie humana, o al menos al colapso de la vida como se conoce actualmente (Altvater, 2014). Por consiguiente, se asume de forma urgente revertir los efectos biogeoquímicos de la especie dominante, ante tal amenaza, de no hacerlo, se espera la extinción en la que otras especies (ciborgs) se darán cuenta de la existencia de la humanidad al encontrar debajo de los suelos todos los desechos de una era industrializadora y productivista.

El concepto de la era del antropoceno no es universalmente aceptada. Quienes lo aprueban insisten que se trata de un punto de inflexión para abordar las fronteras ecológicas planetarias, de modo que recurren al metabolismo social de la Escuela de Viena (véase Toledo, 2008 y 2013) para hacer conciencia y no rebasar dichas fronteras. Por otra parte, quienes lo rechazan alegan que no son todos los seres humanos los responsables de la debacle socio-ecológica que se vive, son solo algunos. Se advierte que el concepto del antropoceno trae consigo un pensamiento moral que involucra a todos los seres humanos, por ello pretende la institucionalización de la naturaleza humana y extra-humana (en adelante las naturalezas) por medio del desarrollo sustentable, modelo que permitiría a futuras generaciones reproducir sus relaciones sociales.

En contraste, se establece el concepto del "capitaloceno" (magistralmente explicado por Andreas Malm, 2015 y 2016), que busca romper con el cerco moral para plantear la cuestión de la crisis ambiental generada por los capitalistas $y$ no por todos los seres humanos como lo enfatiza su contraparte. En ese aspecto, Jason
Moore (2015) propone entender la incesante acumulación de capital en función de (hasta ahora) la amplia disponibilidad de insumos baratos al proceso productivo (fuerza de trabajo, alimentos, energía y materias primas), que han permitido la prácticamente ininterrumpida extracción de ganancias.

Uno de los grandes retos de la eE en su vertiente radical es precisamente enfrentar las propuestas de los economistas ecológicos que promueven matrices metabólicas que racionalizan las entradas energéticas y de materia, así como, sus disipaciones, con el propósito de conformar sociedades más "eficientes" en términos económicos. Como antes se aseveró, en su versión más conservadora, la eE se acerca a la EA en el sentido de utilizar complicados modelos matemáticos para la perpetuación de relaciones económicas favorables a la acumulación, si bien con ciertos requisitos, mismos que se satisfacen precisamente a través del mercado. Se trata, por ejemplo, de la elaboración de entramados instrumentales para el pago de servicios ambientales, que son ampliamente socorridos en la actualidad.

Con frecuencia, las conceptualizaciones que esta versión conservadora hace de los procesos de orden metabólico en distintas escalas (microeconómicas y macroeconómicas), que van orientadas al abordaje de la problemática de las leyes de la termodinámica y la finitud planetaria, se acerca cualitativamente al concepto neoclásico del capital natural, muy distante de la apreciación fundamental de Marx de que el capital es una relación social. Daly (principalmente en los capítulos seis y nueve), quien está sumamente consciente de "los usos y abusos del capital natural", añade otra forma de "capital" como uno de los límites al crecimiento: el capital moral, que se desgasta en los procesos desarrollistas (Daly, 2015).

En sentido contrario al recién expuesto, más enérgica es la vertiente crítica de la EE que se acerca al llamado posdesarrollo (Escobar, 2012), al plantear un orden metabólico desde la vía campesina y el concepto del buen vivir (Cariño, Ángeles, Castorena y Amao, 2014 y en general, el volumen coordinado por Delgado, 2014). Estas conceptualizaciones, emanadas 
de América Latina, van muy frecuentemente acompañadas de movimientos de resistencia por parte de los pueblos originarios en defensa de los comunes tradicionales. Es decir, el campesino se encuentra en la posición de sujeto ecológico por excelencia, debido precisamente a sus afanes por mantener alejadas sus tierras o los bienes comunes fuera del orden metabólico capitalista, más bien, como un "afuera" de la acumulación de capital (Luxemburgo, 1967; Harvey, 2004; De Angelis, 2012).

Las vertientes conservadora y crítica de la EE, al estar pensadas sobre todo en los países de mayores ingresos del Norte global, pondrían en duda las alternativas de los científicos sociales que proponen las cosmovisiones de las comunidades originarias como una salida a la crisis civilizatoria: sus discusiones se vinculan con los intercambios que suceden específicamente en esos espacios, lo que hace poco factible que sus contribuciones teóricas abarquen las epistemologías del Sur o el diálogo de saberes. Por otra parte, es dudoso que esas epistemologías, fundamentadas en una orientación casi exclusivamente local, sean efectivas para enfrentar a nivel global los retos que le imponen el capitalismo neoliberal y la urbanización planetaria evidentemente en apogeo (véanse Roberts, 2016 y Lefebvre, 1989, respectivamente). Más bien, traen a la memoria la discusión de Marx con respecto a las "robinsonadas", referente a la crítica del intento de un retorno a un pasado soñado como paradisíaco ${ }^{4}$.

\section{LA RECUPERACIÓN DEL METABOLISMO SOCIAL DE MARX}

En Biología y Química, el término metabolismo refiere a los procesos en los que una célula o un organismo convierte nutrientes en materia viva (el metabolismo constructivo), o bien, reduce el protoplasma a sustancias simples para el desempeño de diversas funciones (el metabolismo destructivo) (OED, 1971, p. 378). El trabajo del fisiólogo prusiano Schwann de 1839, Mikroskopische untersuchungen übereinstim-

4 La palabra deriva de la obra Robinson Crusoe, de Daniel Defoe (2017). mung in der struktur und dem wachstum der tiere und pflanzen (citado en Foster, 2000, p. 248) colocó en el centro de la atención una formación metabólica celular, la cual impactó en la Química, en la Filosofía, etc., configuró nuevas interrelaciones entre el ser humano con su ambiente, posteriormente se convirtió en una categoría empleada por Marx para explicar un complejo circuito en las sociedades capitalistas desde un plano particular o general, por supuesto, tenía conocimiento de las obras de los fisiólogos, en ese sentido había estudiado a Schwann en 1864, este último ejerció influencia en el químico Liebig, quien realizó una crítica de los robos de los nutrientes al señalar a Gran Bretaña que sustraía de Irlanda la fertilidad de sus tierras (Ibíd.). En Marx, el concepto aparece en el capítulo vi de los Grundrisse, como parte de la explicación del proceso de circulación del capital. Marx advierte que el cambio de forma y el cambio de materia suceden de manera simultánea en ese proceso (Marx, 1973, p. 667-668). Foster afirma que el teórico alemán empleaba ese concepto para:

[...] describir el conjunto de necesidades y relaciones, complejo, dinámico, interdependiente, que se originaba $y$ se reproducía constantemente, en forma alienada, bajo el capitalismo, y también la cuestión de la libertad humana que suscitaba. Todo ello podía considerarse relacionado con el modo en el que el metabolismo humano con la naturaleza se expresaba a través de la organización concreta del trabajo humano. El concepto de metabolismo adoptaba un significado ecológico específico y un significado social general (2000, p. 244-245).

El metabolismo está presente en el tomo I de El Capital (Marx, 1976, p. 283-290 citado en Foster, 2000), donde de manera similar a los Grundrisse se le ubica en un apartado referente a un circuito con el proceso de producción en cuanto a la circulación de la mercancía, el trabajo socialmente necesario y el dinero que servía como medida de valor para adquirir más mercancías, así como también, materia prima $y$ fuerza de trabajo para poner en marcha un 
ampliado proceso de producción, el cual se iba complejizando en el tomo II y III (Marx, 1999). Así, el Stoffwechsel para Marx representaba (aún lo es) un circuito de transferencias entre la sociedad y la naturaleza a través del trabajo encargado de mediarlo y regularlo (Clark y Foster, 2012) o más específicamente, el trabajo es el proceso de intercambio del ser humano con y en la naturaleza, mit und in der Natur (Ruben, 2004).

Para el teórico alemán iba más allá de una analogía que no logró teorizar y explicar con profundidad (Harvey, 2014); es importante señalar que el metabolismo social ha estado reinterpretándose para entrar a un análisis más profundo sobre la degradación del suelo o de la tierra. Si bien, Foster (2000) argumenta que Marx tuvo una visión sobre la sostenibilidad que conducía a un pensamiento ambiental al precisar que la tierra se debía de entregar mejorada, la interpretación es que para el autor de la obra El capital, los procesos sociometabólicos representaban más generalmente y con mayor fidelidad el circuito entre el ser humano $y$ la tierra. Los procesos de producción y de trabajo en el capitalismo avanzado se mantienen, en su esencia, como los manifestó Marx, en particular aquellos que constituyen la base material de este modo de producción.

Lo que ha cambiado es la comprensión del metabolismo social, desprendiéndose un dualismo en cuanto a la separación del ser humano con la naturaleza extra-humana, debido a lo cual irrumpe un nuevo circuito que se asocia con la degradación ambiental, y la manera de repararla o evitarla. La Ee radical contrapone el anterior pensamiento porque un metabolismo coevolucionista únicamente es posible con el rompimiento del proyecto civilizatorio moderno (Foster, 2000; Burkett, 2008).

Sin la existencia de un cambio radical de modo de producción, el metabolismo social se ha ido alejando de su propuesta inicial, por lo que aparecen diversos modelos de metabolismos (el metabolismo industrial, el metabolismo socioeconómico, el metabolismo socioecológico, el metabolismo urbano, el metabolismo rural, etc.), cada uno con metodologías diferentes para ajustarse a las necesidades económicas de determinado espacio o territorio. Algunos fomentan el crecimiento económico por medio del desarrollo sustentable, otros animan a la construcción de mundos alternos con el posdesarrollo ${ }^{5}$.

Con estos modelos funcionalistas y deterministas, las primigenias ideas de Marx en torno al ser genérico o Gattunsgwesen, combinación inseparable de naturaleza y sociedad, han sido alineados a la racionalidad económica, para centrarse principalmente en los procesos de conciencia y cambios en los "estilos de vida" para continuar reproduciendo el crecimiento económico. En contraste, desde la eE radical se retoma el metabolismo social con el propósito de comprender el orden metabólico de las sociedades capitalistas.

Lo dicho remite a la inserción por Marx del Stoffwechsel en el tomo I de El capital, al no reducirlo a un circuito de aspectos fisiológicos y naturales, ni tampoco su operación, ni mucho menos convertir los objetos producidos (por el ser humano) en sujetos para lograr una economía para la vida como promueve la teología de la liberación. Más bien, lo que trataba de enfatizar era su contenido material desde una formación histórica que, en aquel momento, tenía como fin de cuentas, la producción y la reproducción de la vida inmediata (proceso estructurado de crecimiento).

A partir de los preceptos originarios, es necesario trasladar el metabolismo social al capitalismo avanzado, que se fundamenta principalmente en la circulación global de mercancías, que permite su movilización a cualquier espacio, en la financiarización y en la constante flexibilización y precarización de la fuerza de trabajo. En estas circunstancias, interpretaciones del metabolismo como las adelantadas por las escuelas de Viena (Klagenfurt) y Wuppertal, aunque extremadamente relevantes por los detallados análisis técnicos que generan, resultan insuficientes. Si bien, parecen igualmente limitados los planteamientos de las alternativas y salidas que, con

$5 \quad$ Se notará que esta crítica se asemeja al planteamiento de Barkin, Fuente y Tagle (2012), sin necesariamente coincidir en todo. 
base en las teorías del posdesarrollo, pretenden situarse al exterior del capitalismo, aunque la exteriorización pueda ser resistencia. Como sugieren Barkin, Fuente y Tagle (2012), es imperativo incorporar el marxismo de forma decidida.

\section{LA BRECHA METABÓLICA: LA PERMANENTE CONTRADICCIÓN DE LA MERCANTILIZACIÓN DE LAS NATURALEZAS Y LA ACUMULACIÓN DE CAPITAL}

Los artífices del Manifiesto comunista centraban el desarrollo histórico de las fuerzas productivas como factor determinante en cada sociedad (Marx y Engels, 2011; Schmidt, 2013). La economía política $y$ la geografía crítica han venido configurando una vertiente actualizada de este enfoque para explicar las formas en que el capital, los fenómenos intensivos del sistema, debido a su superioridad en el control del espacio y tiempo, afectan decisivamente a la socio ecología (Harvey, 1998).

Se sostiene que el modo de producción capitalista está en constante renovación, ya que sus transformaciones al ambiente acelera el cambio climático que es de alcance global (Malm, 2016). En atención a esto, desde los presupuestos categóricos marxistas se busca dar respuesta a la tensión entre el capitalismo y la naturaleza, el cual remite a la contradicción general entre el valor de uso y el valor de cambio en El capital, que llevó al teórico alemán a deducir la explotación del trabajo (Marx, 1999).

La contradicción entre capitalismo y naturaleza se fortaleció con la consolidación del modo de producción capitalista en la época de la colonia. En particular, las tierras del Nuevo Mundo que sirvieron para asegurar la superioridad de la industria europea. Las colonias fueron factores clave en el proyecto civilizatorio eurocéntrico, quedando este hecho plenamente representado por dos fronteras mercantiles: la minería, con la extracción de la plata y la agricultura, con el cultivo de la caña de azúcar (Moore, 2003).

La extracción de la plata en América cobró importancia al monetizar la economíamundo europea para evitar volver a la autarquía regional (Ibíd.). Los flujos de plata abonaron al fortalecimiento de la presencia e influencia europea en Asia, en especial en China (Mann, 2012). Se dio entonces literalmente una primera globalización, estableciéndose un circuito comercial entre Europa, las Islas Filipinas y China centrado en la producción de plata de México y Potosí.

El capitalismo se arraigaba globalmente como estrategia de desarrollo desigual, subordinaba a los señores de la tierra al mercado mundial $y$ al mismo tiempo, les otorgaba incentivos para incorporarse al nuevo sistema. El mecanismo de crédito surgido de los caudales de plata que se importaban en Europa ( $y$ en China, con otros efectos), ayudó a la creación de una división dispareja del trabajo para generar un sistema internacional de peonaje por la deuda: con la actividad minera, desde el continente americano se conformaba una nueva división trasatlántica del trabajo entre la ciudad y el campo (Moore, 2013a).

No obstante, la extracción de la plata fue insuficiente para hibridar el desarrollo del capitalismo. Se requirió también la plantación de caña de azúcar, representativa de la esclavitud moderna, que fue de gran importancia en los procesos de globalización de la época, pues el azúcar proveía una fuente sumamente barata de calorías para la masa trabajadora que laboraría posteriormente en la industrialización europea, en consecuencia, surgieron complejos de plantaciones de caña a base de trabajo esclavo principalmente en las islas atlánticas, en Brasil $y$ en el Caribe (Moore, 2003).

La plantación de azúcar implementó un nuevo medio para organizar el trabajo (la esclavitud moderna) con un nuevo medio de organización de la tierra (el monocultivo) (Ibíd.). La plata y el azúcar en el capitalismo temprano no eran las únicas fronteras mercantiles pero le dieron vida a todas las fuentes de sustento, principalmente las comerciales entre las que destacaron: los cultivos de cereales, la silvicultura y la ganadería (Ibíd.).

El modo de producción capitalista demostró su eficiencia en comparación con otros modos de producción en sus formas de acumulación de capital y la aplicación de la tecnología a las actividades económicas, que resultó en una inusitada dinamización de las economías una vez entrada 
la revolución industrial a partir del siglo xviII. Para Marx, la acumulación y su reproducción a escala ampliada en el tomo II de El capital, la comprendió a través de la determinación de:

[...] la valorización del valor del capital desembolsado, es decir, en primer lugar, por la producción de la mayor cantidad posible de plusvalía; $y$ en segundo lugar, por la producción de capital, y consiguientemente por la transformación de la plusvalía en capital. Pero, a su vez, la acumulación o producción en escala ampliada, que, como medio para una producción cada vez más extensa de plusvalía $y$, por tanto, para el enriquecimiento del capitalista, aparece como la finalidad personal de éste y va implícitamente en la tendencia general de la producción capitalista, se convierte, al desarrollarse, en una necesidad para todo capitalista individual (Marx, 1987, p. 71).

Rosa Luxemburgo enfatizó la dependencia de la acumulación de capital de una fuente externa (un afuera) para la obtención de recursos, en el sentido de que la continuación de la acumulación ampliada debía abarcar a las sociedades no capitalistas como mercado y fuente de alimentación para la obtención de fuerza de trabajo y de materia prima, por un lado, y como salida a la producción manufacturera, por el otro (Luxemburgo, 1967).

La teórica polaca advirtió sobre la inevitabilidad de una crisis de subconsumo si el capitalismo nacional de su época dependiera exclusivamente de sus posibilidades internas. Creía haber encontrado aquí la principal falla sistémica del capitalismo, pues cuando las poblaciones de esos países no pudieran consumir las mercancías producidas se daría el colapso, a menos que la oferta excedentaria fuera absorbida por la demanda de las colonias. En este sentido, el imperialismo económico se presenta como la forma para la reproducción de la acumulación de capital ${ }^{6}$.

6 Marx y Engels no elaboraron ninguna teoría específica del imperialismo, sin embargo, existen frecuentes referencias genéricas sobre el comercio
En el capitalismo avanzado, la acumulación ha pasado por dos grandes etapas: el keynesianismo de la economía del bienestar de la segunda posguerra y el neoliberalismo de nuestra época. En esta era de "acumulación flexible", la generación de ganancias se basa en:

[...] procesos de racionalización, reestructuración e intensificación del control sobre la fuerza de trabajo, el cambio tecnológico, la automatización, la búsqueda de nuevas líneas de productos, de nichos de mercado, la dispersión geográfica hacia zonas de controles laborales cómodos, fusiones y medidas destinadas a acelerar el giro del capital, así como también las estrategias corporativas para combatir la deflación (Harvey, 1998, p. 170).

Hasta la fecha, la acumulación de capital ha resistido, mal que bien, toda suerte de crisis $y$ ha violentado enormemente al planeta en aras de la perpetuación del crecimiento económico. Lo dicho permite subrayar que la expansión de las fuerzas productivas se fundamenta en la mercantilización de las naturalezas, así como también en los procesos de la producción de la naturaleza. Ante esto último, Neil Smith enfatiza que se convierte en un valor de cambio para su incorporación a un circuito económico (Smith, 2008).

La acumulación originaria (o primitiva) de Marx tiene un papel de gran relevancia en su obra, al ocuparse en resaltar el proceso histórico de disociación entre el productor y los medios de producción (De Angelis, 2012). Lo anterior es base fundamental dentro de la concepción materialista de la historia como fuerza motriz del capitalismo que, desde sus inicios, ha sido imperialista. Para Marx, la acumulación originaria representaba una frontera de transición entre el feudalismo y el capitalismo, a saber, una formación prehistórica del capital.

El capitalismo avanzado ha fragmentado el espacio haciendo que la acumulación primitiva no pueda ser referenciada como lo hizo

mundial y los cambios de direcciones de su época (Marx y Engels, 1974). 
el teórico alemán, debido a la existencia de un proceso constante de producción del espacio, cuya intención es crear más medios de producción con el propósito de continuar con las relaciones sociales capitalistas para la acumulación de capital (Lefebvre, 2013). Harvey (2004) hace referencia a "un ajuste espacio-temporal" que resuelve (temporalmente) las crisis del modo de producción capitalista, cuyas soluciones incluyen cada vez más una renovada acumulación primitiva, bautizadas por el teórico inglés como "acumulación por desposesión" (despojo). Este proceso va desde la apropiación violenta de las tierras de los pueblos originarios, hasta la privatización de los servicios de salud y educativos que, hoy por hoy, se consideran necesidades básicas e incluyen, la privatización de los sistemas de pensiones, del espacio urbano, así, la acumulación originaria se ha convertido en un proceso transhistórico.

La teorización sobre el imperialismo económico tiene como base la discusión de Luxemburgo y Lenin. El político ruso concebía al imperialismo como "la última fase del capitalismo", fundamentada en el incremento de la industria $y$ el proceso de concentración de la producción en empresas monopólicas como particularidad del sistema capitalista (Lenin, 1973). Por su parte, Luxemburgo enfatizaba la colocación de productos de los capitalistas en mercados menos desarrollados para obtener materias primas, fuerza de trabajo, alimentos, por ello, resaltaba el desarrollo del mercado internacional, cuya génesis de dominación se basaba en la guerra como medio para abrir el comercio (Luxemburgo, 1967).

En la actualidad se está ante una nueva forma de imperialismo: el imperialismo ecológico. El imperialismo en el capitalismo avanzado no es una fase última en el modo de producción, puesto que no se trata solo de un mercado mundial fundamentado en las tensiones geopolíticas, aunque claramente estas existen. Se destaca la presencia de una forma adicional de imperialismo, el Imperialismo Ecológico (IEcol) que se coloca en la posición compleja y crítica de las actuales dinámicas del modo de producción, principalmente en la organización de las naturalezas para acumular capital.
El IEcol fue empleado por Crosby (1986) para estudiar la expansión biológica de Europa, en particular hacia el Nuevo Mundo.

Los trabajos del IEcol que han salido a la luz destacan las dinámicas de la monopolización de la naturaleza, la acelerada destrucción de ecosistemas, la reducción de la biodiversidad, los diferentes tipos de extractivismo, la biopiratería, el intercambio ecológico desigual, en las cuales sus efectos son más evidentes en los países del sur global. En este tenor, Vega (2006) reclama que el medio ambiente se ha convertido en una mercancía dentro del sistema capitalista, por ello señala el peligro que corre toda la biosfera, para de ahí plantear la pertinencia de la obra del teólogo brasileño Leonardo Boff en el proceso de toma de conciencia con los "nudos" en la cuestión ecológica $y$ los problemas del agotamiento de los recursos naturales, la sostenibilidad de la Tierra y la injusticia social mundial.

Otro ejemplo es el trabajo de Clark y Foster (2012), que destacan las transferencias ecológicas a través de la extracción de guano en Perú por empresas inglesas en el siglo xIx. El saqueo del preciado fertilizante representó una transferencia ecológica desigual, enmarcados por: a) la intensificación del suelo por la actividad agrícola en Gran Bretaña, b) la transferencia de trabajadores chinos a Perú, c) la exportación del fertilizante a los países centrales europeos, d) la degradación del ambiente en Perú y Chile y, e) la Guerra del Pacífico.

Trabajos como estos, que abundan, enriquecen a la articulación de una crítica al interior del pensamiento dialéctico, que recientemente se ha materializado en la obra de Jason Moore (2000, 2003, 2012 y 2015). Como sus antecesores, Moore revela la realidad perversa de la acumulación de capital desde un contexto histórico que igualmente se da en la actualidad. El trabajo del historiador ambiental pretende dejar al descubierto las valoraciones constantes por parte del capital, principalmente en la necesidad de tener disponibles a bajo precio cuatro elementos o factores que son clave para la producción y reproducción: la fuerza de trabajo (aunado el trabajo doméstico), la energía, los alimentos y las materias primas, 
a los que denomina the four cheaps o "los cuatro baratos", para luego engarzarlos con la teoría del valor de Marx.

El objetivo de este autor es sacar a la luz la organización capitalista de las naturalezas y el giro de la incesante acumulación de capital, en la cual emplea el concepto de commodity frontiers o las "fronteras mercantiles". El término refiere a la incesante búsqueda de materiales para abastecer a los países del Norte global, que se ha extendido a los confines más remotos del planeta. Estas fronteras mercantiles pueden caracterizarse por su gran biodiversidad, ubicarse en lugares de importantes reservas minerales o situarse en territorios donde las condiciones climáticas son más favorables para la producción de bienes, como el café, el azúcar, el té y la soya, así como, el caucho y la celulosa, las cuales no se dan bien en otras partes. Si el reemplazo de materiales $y$ energía utilizados por cualquier sociedad es necesario por razones entrópicas, las fronteras mercantiles se hacen sistémicamente necesarias por la acumulación de capital (Moore, 2000).

El capitalismo avanzado, además, despliega en su actual fase neoliberal, una serie de fronteras mercantiles novedosas, como las fronteras mercantiles híbridas. Estas incorporan varias actividades económicas para organizar a los cuatro baratos desde los sectores primarios, secundarios y terciarios. Los procesos de acumulación, al fin y al cabo, buscan conseguir rentas de algo no producido por el capital, es decir, procuran adueñarse de las creaciones de la naturaleza externa para la obtención de ingresos. De ahí la pertinencia de las teorizaciones de la acumulación por despojo de Harvey, que pueden provechosamente combinarse con la acumulación por apropiación y la acumulación por capitalización de Moore.

La acumulación por despojo converge con la acumulación por apropiación para permitir la ampliación del análisis sobre los procesos que tienen su fundamento en una fase de desposesión de medios de producción, la cual trae como efecto una serie de apropiaciones. Los procesos de despojo y apropiación enmarcan las transformaciones de las naturalezas en objetos baratos, casi gratuitos (Moore, 2012), mientras que la etapa de la acumulación por capitalización refiere a las maneras de poner a trabajar los medios de producción y la naturaleza barata de forma intensiva de acuerdo con los desarrollos tecnológicos, con el fin de incrementar la productividad (Moore, 2013b).

Cabe destacar que el historiador ambiental no podía concebir las transformaciones del capital y de la Tierra por separados, más bien, los visualizó como una sola unidad, como lo hizo Marx (Moore, 2013b). No obstante, en el capitalismo existe una "brecha metabólica", una ruptura en los procesos del metabolismo social. La teorización sobre esta separación que violenta la unidad del hombre $y$ la naturaleza que percibió Marx, es según su autor moderno (John Bellamy Foster, editor de la revista Monthly Review), una cosmovisión ecológica que trasciende las fronteras entre las ciencias sociales y las ciencias naturales; para otros, se manifiesta en una destrucción silenciosa, que podría compararse con el lanzamiento de las bombas nucleares en Hiroshima y Nagasaki ${ }^{7}$. Jason Moore contrapone el concepto del "capitaloceno" al más frecuentemente empleado antropoceno, para hacer hincapié en el hecho de que no es el ser humano (anthropos) el responsable de la debacle ecológica, sino el capital. El capitaloceno potencialmente es más catastrófico que aquellas detonaciones nucleares, que meridianamente es de orden social.

\section{CONCLUSIÓN}

En este artículo se pretende mostrar algunas debilidades de las versiones conservadora y crítica de la eE que ponen de relieve los límites de estas corrientes para investigar la naturaleza de las rupturas metabólicas, que cada vez se hacen más evidentes en la era del capitaloceno. La primera adolece, contra toda evidencia, de la ilusión de que la crisis ecológica es resoluble por la acción conjunta del cambio tecnológico $y$ el sistema de precios del mercado, ideas que provienen de la teoría económica neoclásica.

$7 \quad$ Otros más, como bien apunta Foster, ven en ese concepto la negación de la dialéctica (2013). 
La segunda enfatiza la necesidad de retirarse del sistema imperante $y$ crear sus propios mundos alejados del capitalismo. Ambas propuestas tienen innegable grado de contenido positivo: realmente, dentro de ciertos límites, puesto que el cambio tecnológico tiene algunas (importantes) posibilidades de paliar los efectos de la acción humana sobre el entorno. Aunque se puede sostener la validez de carácter local de los postulados de la vertiente crítica. Debe precisarse que estas opciones puedan funcionar en el seno de un sistema económico imperialista que necesita crecer como las plantas y los animales (incluyendo al ser humano) ya que requieren de agua y sustento.

Por una parte, es impensable que los mercados creados por el capitalismo valoren a la naturaleza sobre la ganancia; por la otra, es difícil ver el alejamiento del capitalismo como una solución de aplicación global en un mundo urbanizado que próximamente tendrá 9 mil millones de habitantes. En contraposición con la visión conservadora, la eE radical rompe con la idea de la mercantilización de la naturaleza como solución a la crisis y subraya la tendencia totalizante del capitalismo, que opone fuertes límites a las posibilidades de aislamiento del sistema. El trabajo propone los "cuatro baratos" de Moore (2015) como forma de replantear la teorización sobre la brecha metabólica de Marx, actualizada por Foster (2000), como forma de generar un mayor acercamiento de la Ee a la conceptualización marxista de la naturaleza.

\section{REFERENCIAS}

Cariño, M. M. Ángeles, L. Castorena y D. R. Amao (2014). Buenos pensares-buenos vivires: conceptos de las ciencias sociales para transformar la crisis climática en oportunidades de mitigación y adaptación. En Delgado, G. C. (Coord.). Buena vida, buen vivir: Imaginarios alternativos para el bien común de la humanidad (pp. 307-338). México, D.F: unam, Centro de Investigaciones Interdisciplinarias en Ciencias y Humanidades.

Altvater, E. (2014). El capital y el capitaloceno. Mundo Siglo XXI, 9 (33), 5-15.
Anderson, P. (1984), Modernity and Revolution. New Left Review, (144), 96-113.

Ángeles, M., A. E. Gámez y A. Ivanova (2011). Crisis multidimensional y economía ecológica. En Correa, A. Girón, A. Guillén y A. Ivanova (Coords.), Tres Crisis: Economía, Finanzas y Medio Ambiente (pp. 127-146). México, D.F: Miguel Ángel Porrúa.

Barkin, D., Fuente, M., y Tagle, D. (2012). La significación de una economía ecológica radical. Revista Iberoamericana de Economía Ecológica, 19, 1-14.

Boulding, K. (1966). The economics of the coming spaceship earth. En H. Jarret (Ed.), Environmental quality in a growing economy, resources for the future (pp. 1-14). Baltimore, usa: Johns Hopkins University Press.

Burkett, P. (2008). La comprensión de los problemas ambientales actuales vistos con el enfoque marxista. Argumentos, 21 (56), 21-32.

Clark, B., y Foster, J. (2012). Imperialismo ecológico y la fractura metabólica global. "Intercambio desigual y el comercio de guano/nitratos". Theomai, (26).

Crosby, A. (1986). Ecological imperialism. The biological expansion of Europe, 9001900. Cambridge, England: Cambridge University Press.

Crutzen, P. (2002). Geology of mankind. Nature, 415 (6867), 23-23.

Daly, H. (2009). From a failed growth economy to a steady-state economy. Recuperado de http://ppc.uiowa.edu/sites/default/ files/sites/default/files/uploads/daly_failed_growth_economy.pdf

Daly, H. (2012). Eight fallacies about growth. Recuperado de http:// www.steadystate. org/eight-fallacies-about-growth/

Daly, H. (2015). Essays Against Growthism. Bristol, England: World Economics Association Books.

De Angelis, M. (2012). Marx y la acumulación primitiva: El carácter continuo de los cercamientos capitalistas. Theomai, (26).

Defoe, D. (2017). La vida y las sorprendentes aventuras de Robinson Crusoe. Quebec: Samizdat. 
Escobar, A. (2012). Más allá del desarrollo: post desarrollo y transiciones al pluriverso. Revista de Antropología Social, 21, 23-62.

Foster, J. (2000). La ecología de Marx. Materialismo y naturaleza. Barcelona, España: El Viejo Topo.

Foster, J.B. (2013). Marx and the Rift in the Universal Metabolism of Nature, Monthly Review, 65, 7. Recuperado de https:// monthlyreview.org/2013/12/01/marx-riftuniversal-metabolism-nature/

Foster, J. (2015). Marxism and ecology: Common fonts of a great transition. Recuperado de http:// www.greattransition.org/publication/marxism-and- eco$\log y$

Foster, J., y Burkett, P. (2004). Ecological economics and classical marxism: The Podolinsky bussiness reconsidered. Organization y Environment, 17 (1), 32-60.

Georgescu-Roegen, N. (1996). La ley de la entropía y el proceso económico. Madrid, España: Gráficas Rógar.

Guillén, A. (2015). La crisis global en su laberinto. México D.F., México: uam, Biblioteca Nueva.

Harvey, D. (1998). La condición de la posmodernidad. Investigación sobre los orígenes del cambio cultural. Buenos Aires, Argentina: Amorrortu editores.

Harvey, D. (2004). El nuevo imperialismo: Acumulación por desposesión. Socialist Register, 40, 99-129.

Harvey, D. (2014). Guía de El capital de Marx. Libro primero. Madrid, España: Ediciones Akal, s.A.

Latouche, S. (2010). Farewell to Growth. Londres, Inglaterra: Polity Press.

Lefebvre, H. (2013). La producción del espacio. Madrid, España: Capitán Swing.

Lefebvre, H. (1989). Quand la ville se perde dans une métamorphose planetaire. Recuperado de https://www.monde-diplomatique.fr/1989/05/LEFEBVRE/41710

Leff, E. (2003). Ecología y capital. Racionalidad ambiental, democracia participativa y desarrollo sustentable. México D.F, México: Siglo xx Editores.
Leff, E. (2011). Sustentabilidad y racionalidad ambiental: hacia "otro" programa de sociología ambiental. Revista Mexicana de Sociología, 73 (1), 5-46.

Lenin, V. (1973). Obras, tomo V (1913-1916). Moscú, Rusia: Edición Progreso.

Luxemburg, R. (1967). La acumulación del capital. México, D.F, México: Grijalbo.

Malm, A. (2015). The Anthropocene Myth. Recuperado de http:// www.jacobinmag. com/2015/03/anthropocene-capitalismclimate-change/

Malm, A. (2016). Fossil Capital: The Rise of Steam Power and the Origin of Climate Change. Londres: Verso.

Mann, C. (2012). 1493: Uncovering the World Columbus Created. Nueva York, usa: Vintage Books.

Markantonatu, M. (2013). From the limits to growth to "degrowth": discourses of critique of growth in the crises of the 1970s and 2008. Recuperado de http://www. kolleg-postwachstum.de/sozwgmedia/ dokumente/WorkingPaper/wp5_2013.pdf

Martínez-Alier, J. (2003). Ecología industrial y metabolismo socioeconómico: Concepto y evolución histórica. Economía Industrial, (351), 15-26.

Martínez-Alier, J. (2008). La crisis económica vista desde la economía ecológica. Ecología Política, (36), 23-32.

Martínez-Alier, J. (2011). El ecologismo de los pobres. Conflictos ambientales y leguajes de valoración. Barcelona: Icaria Editorial.

Martínez-Alier, J. y K. Schlüpmann (1991). La ecología y la economía. México DF, México: Fondo de Cultura Económica.

Marx, K. (1973). Grundrisse. Foundations of the Critique of Political Economy (Rough Draft). Londres: Penguin.

Marx, K. (1976). Capital, t. 1. Nueva York: Vintage.

Marx, C. (1987). El capital. Crítica de la economía política. Tomo II. México, DF, México: Fondo de Cultura Económica.

Marx, C. (1999). El capital. Crítica de la economía política. México, dF, México: Fondo de Cultura Económica. 
Marx, C., y Engels, F. (1974). Colonialismo y guerras en China. México DF, México: Ediciones Roca.

Marx, C. y Engels, F. (2011). Manifiesto del partido comunista. México dF, México: Centro de Estudios Socialistas Carlos Marx.

Mill, J. S. (2009). Principles of political economy. Recuperado de https://eet. pixel-online.org/files/etranslation/ original/Mill,\%20Principles $\% 20$ of $\% 20$ Political\%20Economy.pdf

Moore, J. (2000). Sugar and the expansion of the early modern world-economy: commodity frontiers, ecological transformation, and industrialization. Review Fernand Braudel Center, 23 (3), 409-433.

Moore, J. (2003). Nature and the transition from feudalism to capitalism. Review Fernand Braudel Center, 26 (2), 97-172.

Moore, J. (2012). Cheap food and bad money: food, frontiers, and financialization in the rise and demise of neoliberalism. Review Fernand Braudel Center, 33 (2), 225-261.

Moore, J. (2013a). El auge de la ecología-mundo capitalista (I). Las fronteras mercantiles en el auge $y$ decadencia de la apropiación máxima. Laberinto, (38), 9-26.

Moore, J. (2013b). El auge de la ecología-mundo capitalista (II). Las fronteras mercantiles en el auge y decadencia de la apropiación máxima. Laberinto, (39), 21-29.

Moore, J. (2014). De objeto oikeios: La construcción del ambiente en la ecologíamundo capitalista. Sociedad y Cultura, (2), 87-107.

Moore, J. (2015). Capitalism in the web of life. Ecology and the accumulation of capital. London, England: Verso.

O’Connor, J. (2001). Causas naturales. Ensayos de marxismo ecológico. México, D.F, México: Siglo xxi.

OED. (1971). Oxford english dictionary. Reino Unido: Oxford University Press.

Podolinsky, S. (1995). El trabajo del ser humano y su relación con la distribución de la energía. En J. Martínez Alier (Ed.), Los principios de la economía ecológica.
Textos de P. Geddes, S.A. Podolinsky y F. Soddy (pp. 63-136). Madrid. España: Fundación Argentaria-Visor Distribuciones.

Ricardo, D. (1973). The Principles of Political Economy and Taxation. Londres: Everyman.

Ruben, P. (2004). Marx-Begriffe: Arbeit ist Austausch des Menschen mit und in der Natur-das wird auch heute niemand bestreiten. Nur einen kleinen Einwand müsste Marx sich gefallen lassen: Baumeister sind doch Bienen. Recuperado de https://www.freitag.de/ autoren/der-freitag/stoffwechsel-besonderer-art-arbeit

Schmidt, A. (2011). El concepto de naturaleza en Marx. Madrid, España: Siglo xxi.

Schmidt, A. (2013). Para un materialismo ecológico. Utopía y Praxis Latinoamericana, 18 (61), 11-23.

Sevilla, E. (2011). Sobre los orígenes de la agroecología en el pensamiento marxista $y$ libertario. La Paz, Bolivia: Agruco, Plural editores, CDE, NCCR.

Smith, N. (2008). Uneven development, capital, and the production of space. usa: The University of Georgia Press.

Smith, R. (2015). Green Capitalism: The God that Failed. Bristol: World Economics Association.

Toledo, V. (2008). Metabolismos rurales: Hacia una teoría económica-ecológica de la apropiación de la naturaleza. Revista Iberoamericana de Economía Ecológica, $7,1-26$.

Toledo, V. (2013). El metabolismo social: Una nueva teoría socioecológica. Relaciones, (136), 41-71.

Vega, R. (2006). Imperialismo ecológico. El interminable saqueo de la naturaleza $y$ de los parias del sur del mundo. Revista Herramienta, (31).

Fecha de ingreso: 31/05/2017 Fecha de aprobación: 26/09/2017 
